\title{
Profound promotion should be grasped in several dimensions for the innovation and entrepreneurship education in colleges
}

\author{
Yu Chen ${ }^{1, a}$, Jiajia Wang ${ }^{1, b}$ \\ ${ }^{1}$ Taizhou Polytechnic College, Jiangsu Taizhou, China, 225300 \\ a38907447@qq.com, bwangjiajia_99@163.com
}

Keywords: higher education, innovation and entrepreneurship, profound promotion, important path

\begin{abstract}
The era endows innovation and entrepreneurship with new functional orientation and specific mission in the national economy, it also brings opportunities and challenges to colleges. In an effect to solve the problems faced by innovation and entrepreneurship education in colleges, and enhance the employment strength, entrepreneurial capabilities and development potential of college students, we must elaborate plan, fine management, delicate services, precision propulsion, accurate implementation, talents of refinement.
\end{abstract}

\section{Introduction}

In the background of economic development entering the new normal times, innovation driven development has become a national development strategy, innovation and entrepreneurship has also been elevated to an unprecedented height, and has been highly valued by all walks of life. In 2015, the government work report was highlighted that make "public entrepreneurship, mass innovation" as one of "double engines" to promote China's economy continue to move forward ${ }^{[1]}$. On the fifth Plenary Session of the 18th CPC Central Committee, innovation development was on the top of five development concepts, was promoted to the core position of national development, and a clearer signal was released ${ }^{[2]}$. This shows that the Central Committee of the CPC and the State Council have made clear demands on the functional orientation and specific mission of innovation and entrepreneurship in the development of national economy, established the main direction and strategic objectives for the whole society to promote innovation and entrepreneurship.

Innovation and entrepreneurship, the foundation lies in education, and the key lies in talents. Accelerate the "public entrepreneurship, mass innovation ", move towards overall innovation in science, technology, theory, system, culture and so on, the strong support from higher education can not be separated, this is decided by the special status of higher education in the development of the country. As an important "incubator" and "talent pool" of innovation and entrepreneurship, colleges should provide intellectual support and technical services, further provide springhead and qualified staff. Therefore, colleges must always bear in mind their responsibilities and mission, constantly improve and perfect the system of innovation and entrepreneurship education, further promote innovation and entrepreneurship education reform, effort to cultivate more new force and vanguard for the "public entrepreneurship, mass innovation ", make due contribution to the country's innovation and development. This is the deep call of the times for higher education, also the inevitable requirement of the reform and development of higher education.

And what makes us happy is that, with promotion of the core position of innovation and development in the overall situation of national development, the cultivation of innovative talents is becoming more and more important and attract more attention, gradually rise to the national strategic level. In order to give full play to the role of colleges and universities in cultivating innovation and entrepreneurship talents, make the university make greater contribution to the national innovation and development strategy, in May this year, the State Council issued "Opinions on deepening the reform of innovation and entrepreneurship education in colleges and universities", it has focused on 9 tasks. This underlines the importance of innovation and entrepreneurship education in the country, 
also brings a rare opportunity for the innovation and entrepreneurship education in colleges and universities.

\section{The present situation and main problems of innovation and entrepreneurship education in China's colleges}

In recent years, colleges innovation and entrepreneurship education has made great progress, personnel training mechanism and quality standards have been preliminarily established, the level of financial support has been remarkably improved, teacher training system has taken shape, the reform of education and teaching have been deepening, the quality of teaching in the first class has obviously improved, the number of the second classrooms is gradually increasing, theoretical teaching and practical teaching has intersected each other, the activities of innovation and entrepreneurship are becoming more and more frequent, and the atmosphere is becoming increasingly strong, some practical teaching materials with high quality and effective teaching methods have been formed, a batch of innovation and entrepreneurship educational achievements and advanced models have emerged. What is even more exhilarating is that, some provinces, cities colleges and universities have conducted cutting-edge research, institutes of innovation and entrepreneurship have been established in succession. Zhejiang Province explicitly requested ${ }^{[3]}$, the colleges and universities in the province should establish institutes of entrepreneurship in general before the end of March 2016, improve and perfect the corresponding management system and operation mechanism, Jiangsu province also has corresponding incentives, encourage colleges and universities in the province to try first. Some colleges and universities have spontaneously established innovation and entrepreneurship colleges, some universities have promoted innovation and entrepreneurship to discipline construction and university construction. Nanjing University has made it clear, we should promote the construction of the subject of "entrepreneurship" and the construction of "entrepreneurial university".

Although the innovation and entrepreneurship education in colleges and universities in China has achieved some success, most universities started relatively late, the starting point was relatively low, mature molding experience and practice is still relatively less, some universities are still in the early stages of exploration, implementation effect can only be regarded as just passable, some good and some bad. Some places, colleges and universities do not pay enough attention to innovation and entrepreneurship education, the protection of the policy conditions has not yet been fully implemented, the status and role of innovation and entrepreneurship education in the university evaluation system is not prominent enough; promote the revision and perfection of teaching materials, construction of teaching staff, the consciousness of teaching method reform is not strong, the curriculum system of innovation and entrepreneurship education has not yet fully formed, the teaching management is not standard enough; the construction of teaching staff does not meet the needs of the reform and development of innovation and entrepreneurship education, overall quality should be improved urgently; the effective integration of resources is not enough, the pattern of overall, all-round and whole process of educating people has not yet come into being. Compared with the requirements of the times and the actual needs of "public entrepreneurship and mass innovation", there is still a big gap, and not compatible with the core position of innovation and development.

\section{According to the "three forces" target system to grasp the six dimensions of innovation and entrepreneurship education}

Carry out innovation and entrepreneurship education in a deep-going way, is not only the needs to speed up the implementation of innovation driven development but also the needs to romote higher quality entrepreneurial employment for college students. Only innovation and entrepreneurship education can be regarded as an important platform to promote the all-round development of students, guide more and more students to improve their comprehensive quality in innovation and entrepreneurship activities, take them the strength of employment, the ability to start a business, the potential for development, it could truly create the new force of public entrepreneurship and mass 
innovation. This requires both top level design, sets up an advanced idea of innovation and entrepreneurship education, and needs to do the concept of put down roots, effectively achieve innovative, entrepreneurial education and professional education organic integration, instead of "two skins"; pay more attention to cultivation of the spirit of innovation, the entrepreneurial consciousness and the ability of innovation and entrepreneurship, not just knowledge; effective coverage of all students, not just students who have the will to innovate and entrepreneurial.

\subsection{Elaborate Plan-The basic strategy of promoting innovation and entrepreneurship education.}

Innovation and entrepreneurship education is a systematic project, it involves all aspects of colleges and universities and even society, needs careful planning. First, full participation. Follow up in all directions, multi-level linkage, efforts to create a vivid situation of "everyone cares, everyone involved". Second, full course instruction. Specific implementation opinions should be formulated and promulgated, make sure that each student receives the full course of instruction, and establishs high quality occupation career planning. Third, comprehensively promote. To deepen the "school, institute, class" three linkage work mechanism. Overall management, clear responsibility, layer by layer, provide strong organizational support.

3.2 Fine Management, this is the inherent requirements to further promote the innovation and entrepreneurship education.

Details determine success or failure, only fine management, could make conditions for the implementation of policies in place. It is a real emphasis on innovation and entrepreneurship education. First is the subdivision level. According to the development goal and the potential of students, students can be divided into academic promotion, employment, business startup, and many other types. Second is to refine management. To strengthen the usual innovation and entrepreneurship education and graduate employment management system construction and information construction, we should improve efficiency. At the same time, strengthen the team construction, establish a relatively stable work team of innovation, entrepreneurship education and career guidance, targeted to improve the quality and level of the team, driven them toward professionalism and expertise. Third is the selected base. To effective integration of internal and external resources, to strengthen the integration of different types, different levels bases cooperation between schools and places, schools and enterprises, do good, do it, and do more the college students' employment bases.

3.3 Delicate Services, this is the inevitable pursuit to further promote of innovation and entrepreneurship education.

The management and service complements each other, mutual support, the quality of the work, directly determines the effectiveness of innovation and entrepreneurship education, we must firmly grasp the key link, provide refined services in place. First is the career planning guidance. We could help freshman establish the occupation career planning. To enable students to learn with goals, and ready for employment. Second is to provide employment skills training. So that students can receive courses and job guidance lectures at school continuity, achieve the course has goals, plans, teaching materials, teaching plans, and teachers. Efforts should be made to improve the curriculum system of innovation and entrepreneurship education. Third is to actively build innovation and entrepreneurship platform. Hold the innovative business plan competition and simulated entrepreneurship competition, let the students get more exercise on different platforms, create conditions for construction of college students' entrepreneurship incubator.

\subsection{Precision Propulsion, this is the effective measures to further promote innovation and} entrepreneurship education.

Scientificly definite the main responsibility and duties, in a timely manner to process tracking, continuously improve the evaluation system is a solid guarantee to ensure the effect of education. First, the subject of department. To build an all-round, the whole process of educating work pattern that is the school plan as a whole, coordinate with departments, responsible for departments, and all staff participation.Among them, the department should play the main role. Second, the process of notification. At the beginning of the year, schools need to make monthly employment work 
breakdown, each unit in accordance with the timing schedule and carry out the work. The school informes departments, professional employment work progress timely, summarize and popularize advanced experience and practice, put forward the improvement measures. Third, results assessment. To establish and improve the innovation and entrepreneurship education employment assessment and evaluation system, and fully demonstrate its position in the assessment system in the colleges and universities, efforts to form a new work pattern of concerted efforts, everybody is responsible, and the highly effective.

3.5 Accurate Implementation, this is the specific goals to further promote innovation education.

The cultivation of innovative talents is not only the results of macro, but also micro, only each specific goal of micro has been accurately implemented, it could provide strong support for the achievement of the overall goals.First is the implementation of the workplace. Let the graduates find satisfactory jobs in a timely manner. Second is policies must be implemented. To strengthen the conditions guarantee, effective implementation of the school, college employment guidance institutions, personnel, venues, funding in place. Third, assign responsibility. To sound professional warning, exit and dynamic adjustment mechanism, timely reduce the enrollment plan which with continue the low employment rate. Establish of joint meeting system, and give full play to its role in drawing up enrollment plans and carrying out new professional demonstration,form of enrollment plan and new professional and employment linkage mechanism.

3.6 Talents of Refinement, this is the fundamental purpose of promoting innovation and entrepreneurship education.

The cultivation of high quality innovative and entrepreneurship talents with solid skills, normative behavior and distinctive personality, is the starting point and end point of innovation and entrepreneurship education, is also the development direction and basic purpose of higher education. First, solid skills. Increase innovative courses credit ratio in the credit structure, reform teaching methods, cultivate students' innovation spirit and practice ability. Second, normative behavior. Through occupation training, social practice and other activities, to improve the students' occupation morals, occupation skill, occupation behavior, occupation style and consciousness etc, make the students' behavior in line with the social, school, enterprise needs. Third is distinctive personality. Provide a good mechanism and conditions for the development of students' personality, create a good sunshine campus cultural, culture sunshine students that have distinctive characteristics.

\section{Acknowledgements}

This work was financially supported by The key Project of Scientific Research Institute of Taizhou Polytechnic College (TZYKY-17-4), and Research project of Party Construction of Taizhou Polytechnic College (DJ2015006).

\section{References}

[1] Li Keqiang. The Annual Government Work Report[N], Economic Daily News, 2015-3-17(1-3)

[2] Compiling group of this book. Counseling reader about Proposal of the CPC Central Committee on formulating the thirteenth five year plan for national economic and social development[M], Beijing: People's Publishing House, 2015:11

[3] Wu yihan, Dong bishui. Universities in Zhejiang before the end of March set up Entrepreneurship[N], China Youth Daily, 2016-2-23(4). 